viện, mạch nhanh liên tục trung bình trên 180 lần/ phút được theo dõi sát và chỉ có 15 bệnh nhân được đo huyết áp, nhận định kết quả tẳng nhẹ so với tuổi. Phân độ nặng của bệnh nhân khi nhập viện, chủ yếu là ở nhóm bệnh nhân độ $2 b$ nhóm 1 là 58,8\%, độ 2a là 17,5\%, độ 2b nhóm $211,2 \%$, độ 1 có $2,5 \%$, tỷ lệ này phù hợp với vai trò là một bệnh viện Nhi của Hà Nội, là nơi ban đâu chăm sóc trẻ em, do vậy phân lớn trẻ vào viện ở mức độ 2 trở lên, có 2 trường hợp độ 1, nhưng do có bệnh lý kèm theo suy dinh dưỡng và viêm phế quản. Bệnh TCM diễn biến thường nhẹ, chỉ có tỷ lệ nhỏ tiến triển nặng, những bệnh nhân này lại rất cân sự theo dõi chặt chẽ và xử trí kịp thời trong quá trình nằm viện để giảm biến chứng nặng. Trong nghiên cứu có nhiều trẻ chuyển độ nặng sau vài giờ, vài ngày nằm viện. Xét nghiểm tìm virut gây bệnh do EV71 được thực hiện 100\% các bệnh nhân bị CTM nhập viện, kết quả tìm được EV71 (+) chiếm $28,8 \%$, còn lại $71,2 \%$ âm tính hoặc không rõ nguyên nhân gấy bệnh. Cho nên các triệu chứng lâm sàng đặc trưng của bệnh có giá trị cao trong chẩn đoán bệnh. Nghiên cứu của Trân Thị Trang Anh ${ }^{5}$ ở bệnh viện nhi trung ương, có 817 trường hợp đước làm xét nghiệm PCR dịch ty. hâu tìm EV, dương tính chiếm $66,1 \%$, âm tính 33,9\%. Xét nghiệm bạch câu tăng trong trường hợp bênh nhân bị kèm bệnh nhiễm trùng như viêm phễ quản phổi, viêm da mủ. Xét nghiễ̂m công thức máu và CRP tăng ở tình trạng nhiễm khuẩn do các bệnh lý kèm theo, ở nhóm bệnh nhân TCM đơn thuân thì CRP và công thức bạch cầu bình thường, phù hợp với căn nguyên gây bệnh là do virut. Thời gian nằm viện ở nhóm bệnh nhân tay chân miệng trung bình là 5,7 ngày. Bệnh nhân phải điểu trị kéo dài do mắc các bệnh kèm theo hoặc chuyển độ nặng.

\section{KẾT LUẬN}

Bệnh tay chân miệng ở trẻ em là một bệnh dễ lây thành dịch, biểu hiện đa dạng, phân lớn là sốt nhẹ và phát ban phỏng nước ở bàn tay, bàn chân và loét miệng. Bệnh diễn biến thường nhẹ, nhưng cân phải vào viện điêuu trị và theo dõi chuyển độ khi có dấu hiệu biến chứng thân kinh và tim mạch. Xét nghiệm tìm EV71 chỉ gặp $28,8 \%$ cho nên triệu chứng lâm sàng đặc trưng vẫn có giá trị giúp chẩn đoán bệnh TCM.

\section{TÀl LIỆU THAM KHẢO}

1. Takahashi $S$, et al.(2018). Epidemic dynamics, interactions and predictability of enteroviruses associated with hand, foot and mouth disease in Japan. Journal of the Royal Society, Interface. 15(146),

2. Gonzalez G, et al.(2019). Enterovirus-Associated Hand-Foot and Mouth Disease and Neurological Complications in Japan and the Rest of the World. International journal of molecular sciences. 20(20),

3. Hsia SH, et al.(2020). Cardiopulmonary failure in children infected with Enterovirus A71. Journal of biomedical science. 27(1), 53.

4. Ngô Thị Hiếu Minh (2010). Nghiên cứu dịch tễ học, lâm sàng và cận lâm sàng bệnh tay chân miệng ở trẻ em. Luận văn Thạc sĩ Y học, Đại Học Y Hà Nổi.

5. Trân Thị Trang Anh (2013). Một số đặc điểm dịch tễ , lâm sàng, cận lâm sàng bệnh tạy chân miệng ở trẻ em tại khoa truyên nhiếm, bệnh viện nhi trung ương. Khóa luận tốt nghiệp bác sỹ y khoa, Khóa 2007 - 2013, Đại Học Y Hà Nội.

6. Nguyến Kim Thư (2016). Nghiên cứu đặc điểm lâm sàng, cận lâm sàng và căn nguyên vi rút gây bênh Tay Chân Miệng tại Việ̂t Nam. Luân án Tiến sỹ chuyên ngành Truyền nhiễm và các bệnh Nhiệt Đới. Trường Đại học Y Hà Nội.

7. Chatproedaprai S et al (2010). Clinical and Molecular Characterization of Hand-foot-and Mouth Disease in Thailand, 2008-2009. Japanese Journal Infectious Disease. 63(4), 229-33

\title{
KẾT QUẢ ĐIỀU TRỊ UNG THƯ TUYẾN TIỀN LIỆT DI CĂN BẰNG LIẸUU PHÁP ỨC CHẾ ANDROGEN
}

\section{TÓM TẮT.}

Mục tiêu: Đánh giá kết quả điều trị ung thư tiền liệt tuyến di căn bằng liệu pháp ức chế androgen. Đối tượng và phương pháp nghiên cứu: Nghiên cứu

*Trường Đại học Y Hà Nội

Chịu trách nhiệm chính: N̉guyễn Anh Tuấn

Email: dranhtuan2312@gmail.com

Ngày nhận bài: 2.8.2021

Ngày phản biện khoa học: 29.9.2021

Ngày duyệt bằi: 5.10 .2021

\section{Nguyễn Anh Tuấn', Vũ Hồng Thăng ${ }^{1}$}

mô tả cắt ngang trên 39 bệnh nhân ung thư tiền liệt tuyến giai đoạn di căn và được trị liệu bằng ức chế androgen (ADT) tai bênh viên $\mathrm{K}$ tữ tháng 1/2017 đến tháng 6/2021. Kết quả: Triệu chứng lâm sàng thường gặp tại thời điểm chẩn đoán: mất ngủ $(66,7 \%)$, tiểu khó $(69,2 \%)$, tiểu nhiều lần $(56,4 \%)$, đau xương $(59,0 \%)$. Có $71,8 \%$ bệnh nhân lựa chọn cắt tinh hoàn bằng ngoại khoa, 28,2\% cắt tinh hoàn bằng nội khoa. Sau 3 tháng điều trị, các triệu chứng thuyển giảm đáng kể: mất ngủ $(17,9 \%)$, tiểu khó $(20,5 \%)$, tiểu nhiều lần $(5,1 \%)$, đau xương $(28,2 \%)$. Thời gian sống thêm không tiến triển (PFS) trung bình là 
$26,61 \pm 3,65$ tháng. PFS ở nhóm cắt tinh hoàn ngoai khoa là 22,62 $\pm 3,45$ tháng, ở nhóm cắt tinh hoàn nội

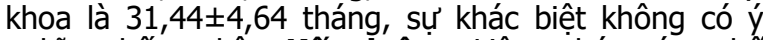
nghĩa thống kê. Kết luận: Liệu pháp ức chế androgenlà điều trị nền tảng và hiệu quả trong ung thư tiền liệt tuyến giai đoạn di căn.

Tư khóa: Ung thư biểu mô tiền liệt tuyến, giai đoạn di căn, liệu pháp ức chế androgen.

\section{SUMMARY \\ RESULTS OF TREATMENT METASTATIC PROSTATE CANCER BY ANDROGEN DEPRIVATION THERAPY}

Objective: To evaluate the efficiency of androgen deprivation therapy in metastatic prostate cancer. Patients and methods: Description study of 39 patients with metastatic prostate cancer who givenandrogen deprivation therapy between 2017 and June 2021. Results: Common clinical symptoms at the time of diagnosis: insomnia $(66,7 \%)$, dysuria $(69,2 \%)$, urinary frequency $(56,4 \%)$, bone pain $(59,0 \%)$. In which, $71,8 \%$ of patients choose surgical orchiectomy. After 3 months of treatment, the symptoms were significantly reduced: insomnia $(17,9 \%)$, dysuria $(20,5 \%)$, urinary frequency $(5,1 \%)$, bone pain $(28,2 \%)$. The mean progression-free survival (PFS) was 26,61 $\pm 3,65$ months, in the surgical orchiectomy group was $22,62 \pm 3,45$ months, in the medical castration was $31,44 \pm 4,64$ months, the difference was not statistically significant between two groups. Conclusion: Androgen deprivation therapy is the cornerstone and effective treatment in metastatic prostate cancer.

Key words; prostate cancer; metastatic; Androgen deprivation therapy.

\section{I. ĐẶT VẤN ĐỀ}

Ung thư tiên liệt tuyến là một trong các ung thư phổ biến nhất ở nam giới, đặc biệt là tại các nước phát triển. Theo ước tính của GLOBOCAN 2018, trên thế giới có 1.276 .100 trường hợp mắc mới, với tỷ suất 29,3/100.000, và 359.000 trường hợp tử vong do UTTTL, với tỷ suất $7,6 / 100.000$ [1]. Ung thư tiền liệt tuyến là bệnh diễn biến chậm trong nhiều năm, và khi có biểu hiện lâm sàng, bệnh đã ở giai đoạn muộn.

Ung thư tiên liệt tuyến có thể được điêuu trị bằng nhiêu phương pháp khác nhau, gồm phấu thuật, xạ trị, nội tiết, hóa trị và miễn dịch tùy theo giai đoạn bệnh, yếu tố nguy cơ và tiên lượng sônng thêm của bệnh nhân. Khi bệnh nhân ở giai đoạn di căn, liệu pháp ức chế androgen bao gồm cắt tinh hoàn nội khoa và ngoại khoa là điêu trị nền tảng, đóng vai trò quan trọng hàng đâu.

Cho tới nay còn ít nghiên cứu trong nước đánh giá về hiệu quả của liệu pháp ức chế androgen trong điều trị ung thư tiên liệt tuyến di căn. Vì vậy, chúng tôi tiến hành nghiên cứu này với mục tiêu: Đánh giá kêt quảđiều trị ung thu tiền liệt tuyến di căn bằng liệu pháp ức chế androgen.

II. ĐỐI TƯỢNG VÀ PHƯƠNG PHÁP NGHIÊN CỨU

2.1. Thời gian và địa điểm: Chọn các bệnh nhân được điều trị từ1/2017 đến 30/6/2021 tại Bệnh viện K cơ sở Tân Triều.

\section{2. Đối tượng nghiên cứu}

2.2.1. Tiêu chuẩn chọn bệnh nhân nghiên cứu:

- Chẩn đoán ung thư TTL di căn:

+ Có kết quả chẩn đoán mô bệnh học khẳng định ung thư TTL.

+ Có bằng chứng di căn trên xạ hình xương và/hoăc tổn thương di căn trên CT/MRI. Nếu hach bạch huyết là bằng chứng di căn duy nhất, kích thước hach phải $\geq 2 \mathrm{~cm}$, mất cấu trúc hạch.

- Được điêuu trị bằng liệu pháp ức chế androgen có thể kết hợp với thuốc kháng androgen thế hệ thứ nhất (Bicalutamide).

- Hồ sơ lưu trữ đủ thông tin nghiên cứu

\subsubsection{Tiêu chuẩn loại trừ}

- Giải phẫu bệnh không phải là ung thư biểu mô tiền liệt tuyến

- Có ung thư thứ hai

- Bệnh nhân được điều trị kết hợp với hóa chất, các thuốc nội tiết khác (docetaxel, abiraterone, ...)

2.3. Cõ mẩu: cõ mẫu toàn bộ (các bệnh án đây đủ thông tin từ1/2017-30/6/2021)

2.4. Phương pháp nghiên cứu: mô tả cắt ngang

2.5. Cách thức tiến hành:

- Thu thập hồ sơ bệnh án theo mẫu bệnh án

- Chọn bệnh nhân đủ tiêu chuẩn vào nghiên cứu

- Ghi nhận các triệu chứng lâm sàng và cận lâm sàng trước khi điều trị.

- Đánh giá bệnh nhân sau 1 tháng, 3 tháng, 6 tháng và 12 tháng điêu trị.

2.6. Phân tích số liệu:số liệu được nhập và phân tích sử dụng phân mềm SPSS 21.0. Các chỉ tiêu nghiên cứu bao gồm:

- Tỷ lệ đáp ứng trên triệu chứng lâm sàng.

- Thời gian sống thêm không tiến triển (PFS).

\section{7. Đạo đức nghiên cứu}

- Phương pháp điêu trị đã được áp dụng ở nhiều nước trên thế giới.

- Có sự cho phép của bệnh viện.

- Có sự đồng ý hợp tác của bệnh nhân.

\section{KẾT QUẢ NGHIÊN CỨU}

\section{1 Đặc điểm đối tượng nghiên cứu}

Tuổi trung bình của nhóm bệnh nhân là $68,90 \pm 6,85$ tuổi, nhóm tuổi $65-79$ tuổi chiếm $65,1 \%$. 
Bảng 1: Các triệu chứng lâm sàng

\begin{tabular}{|c|c|c|}
\hline $\begin{array}{c}\text { Triệu chứng lâm } \\
\text { sàng }\end{array}$ & Tân suất & $\begin{array}{c}\text { Tỷ lệ } \\
\text { \% }\end{array}$ \\
\hline Mất ngủ & 26 & 66,7 \\
\hline Tiếu khó & 27 & 69,2 \\
\hline Tiếu nhiều lần & 22 & 56,4 \\
\hline Đau xương & 23 & 59,0 \\
\hline
\end{tabular}

Nhận xét: Các triệu chứng lâm sàng thường gặp là mất ngủ $(66,7 \%)$, tiểu khó $(69,2 \%)$, tiểu nhiêu lần $(56,4 \%)$, đau xương $(59,0 \%)$.

Bảng 2: Đặc điểm phương pháp điều trị

\begin{tabular}{|c|c|c|}
\hline Phương pháp & Số BN & Tỳ lệ \% \\
\hline Cắt tinh hoàn ngoại khoa & 28 & 71,8 \\
\hline Cắt tinh hoàn nội khoa & 11 & 28,2 \\
\hline
\end{tabular}

Nhân xét: $71,8 \%$ bênh nhân lưa chọn cắt tinh hoàn ngoại khoa, chỉ có $28,2 \%$ lựa chọn cắt tinh hoàn nội khoa.

\section{2. Đánh giá đáp ứng}

Bảng 3: Đáp ứng trên các triệu chứng lâm sàng

\begin{tabular}{|c|c|c|}
\hline Triệu chứng lâm sàng & Số BN & Tỷ lệ \% \\
\hline Mất ngú & 7 & 17,9 \\
\hline Tiếu khó & 8 & 20,5 \\
\hline Tiếu nhiều lần & 2 & 5,1 \\
\hline Đau xương & 11 & 28,2 \\
\hline
\end{tabular}

Nhận xét: Sau 3 tháng điều trị, các triệu chứng lâm sàng giảm rõ rệt: mất ngủ $(17,9 \%)$, tiểu khó $(20,5 \%)$, tiểu nhiều lần $(5,1 \%)$, đau xương $(28,2 \%)$.

triên

Bảng 4: Thời gian sông thêm không tiên

\begin{tabular}{|c|c|c|}
\hline Phương pháp điều trị & PFS (tháng) & Giá trị p \\
\hline Cắt tinh hoàn ngoại khoa & $22,62 \pm 3,45$ & \multirow{2}{*}{0,138} \\
\hline Cắt tinh hoàn nội khoa & $31,44 \pm 4,64$ & \multirow{2}{*}{$\mid$} \\
\hline PFS trung bình & $26,61 \pm 3,65$ & \\
\hline
\end{tabular}

Nhận xét: Thời gian sống thêm không tiến triển trung bình là $26,61 \pm 3,65$ tháng. PFS ở nhóm cắt tinh hoàn bằng ngoại khoa là $22,62 \pm 3,45$ tháng, ở nhóm cắt tinh hoàn bằng nội khoa là $31,44 \pm 4,64$ tháng, sự khác biệt giữa 2 nhóm không có ý nghĩa thông kê với $p=0,138$.

\section{BÀN LUÂ̂N}

Nghiên cứu của chúng tôi đánh giá hiệu quả điều trị liệu pháp ức chế androgen trên 39 bệnh nhân UT TLT giai đoạn di căn. Tuổi trung bình của bệnh nhân là $68,90 \pm 6,85$ tuổi (từ 57 đến 85 tuổi), trong đó nhóm tuổi 65 đến 79 chiếm tỷ lệ cao nhất $65,1 \%$. Kết quả này cũng tương đương với độ tuổi của bệnh nhân ung thư giai đoạn di căn được báo cáo trong nghiên cứu của tác giả Lê Thị Khánh Tâm [2], với tuổi trung bình $71,9 \pm 7,7$ năm, với $76 \%$ bệnh nhân thuộc nhóm tuổi 65 đến 79 tuổi; tương tự trong nghiên cứu của Gandaglia, Abdollah với tuổi trung bình là 75 (từ 67 đến 82) [3].

Các triệu chứng lâm sàng thường gặp tại thời điểm chẩn đoán là tiểu khó $69,2 \%$, tiểu nhiều lần $56,4 \%$, đau xương $59,0 \%$, mất ngủ $66,7 \%$. Tỉ lệ đau xương trong nghiên cứu của chúng tôi tương đồng với kết quả của tác giả Lê Thị Khánh Tâm 58,7\% [2].

Trong nghiên cứu của chúng tôi, phần lớn bênh nhân lựa chọn phương pháp cắt tinh hoàn bằng phẫu thuật với tỉ lệ $71,8 \%$, cao hơn kết quả của tác giả Lể Thị Khánh Tâm (52\%) [2]. Cắt tinh hoàn ngoai khoa là một thủ thuât đơn giản và tương đối hiệu quả, nồng độ testosteron nhanh chóng giảm xuống mức cắt tinh hoàn trong vòng 2-3 ngày đầu [4]. Ở nhiều quốc gia, phẫu thuật cắt bỏ tinh hoàn 2 bên vẫn là một liệu pháp chuẩn trong điều trị nội tiết ung thư tiền liệt tuyến di căn, không chỉ bởi vì hiệu quả giảm nhanh những triệu chứng như chèn ép tủy sống, tắc nghẽn đường tiết niệu ngay lâp tức mà còn lợi ích về mặt kinh tế, tuân thủ điều trị. Cắt tinh hoàn nội khoa với cơ chế làm giảm sản xuất testosterone thông qua tác động trên trục hạ đồi-tuyến yên [5]. Có 2 nhóm thuốc được sử dụng gồm thuốc đồng vận $\mathrm{GnRH}$ và đối vận $\mathrm{GnRH}$, trong đó thuốc đồng vận được sử dụng rộng rãi hơn cả. Khi sử dụng thuốc đồng vận GnRH sẽ có sự gia tăng tạm thời LH dẫn tới tăng nồng độ testosterone trong máu tạo ra cơn bùng phát triệu chứng: các triệu chứng biểu hiện nặng hơn như chèn ép tủy sống hay tắc nghẽn đường tiết niệu [6]. Để ngăn ngừa cơn flare này, việc sử dụng thuốc kháng androgen (bicalutamide, flutamide) trước 7-10 ngày trước khi cắt tinh hoàn bằng thuốc đồng vận $\mathrm{GnRH}$ nên được đưa vào thực hành lâm sàng thường quy [4].

Cắt tinh hoàn bằng nội khoa hay ngoại khoa đều đạt hiệu quả tương đương và đều nên bắt đâu sớm ngay sau khi bệnh nhân được chẩn đoán ung thư tiền liệt tuyến giai đoan di căn. Nghiên cứu của tác giả Kaisary và cộng sự tiến hành trên 292 bệnh nhân ung thư tiền liệt tuyến được cắt tinh hoàn bằng zoladex và ngoại khoa cho thấy rằng không có sự khác biệt về tỉ lệ đáp ứng (lần lượt là $71 \%$ và $72 \%, p=0,91$ ), thời gian đến khi đáp ứng $(9,0$ và 10,2 tuân, $p=0,51)$ và thời gian duy trì đáp ứng $(53,7$ tuần và 50,1 tuần) [7].

Về đáp ứng trên lâm sàng, sau 3 tháng điều trị, các triệu chứng giảm rõ rệt, với tỉ lệ mất ngủ $(17,9 \%)$, tiểu khó $(20,5 \%)$, tiểu nhiều lần $(5,1 \%)$, đau xương $(28,2 \%)$. Kết quả nghiên cứu của chúng tôi tương đồng với của tác giả Lê Thị Khánh Tâm trên 75 bệnh nhân ung thư tiền liệt 
tuyến giai đoạn di căn được điều trị bằng liệu pháp ức chế androgen [2].

Về lợi ích về sống thêm, thời gian sống thêm không tiến triển (PFS) trung bình của nhóm bênh

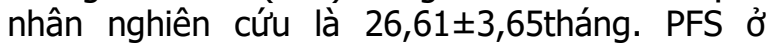
nhóm cắt tinh hoàn ngoại khoa là 22,62 3,45tháng, ở nhóm cắt tinh hoàn nội khoa là

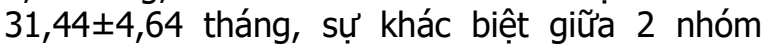
không có ý nghĩa thống kê với $\mathrm{p}=0,138$. Tuy cơ chế 2 phương pháp cắt tinh hoàn khác nhau nhưng phần lớn bệnh nhân cuối cùng sẽ tiến triển đến kháng cắt tinh hoàn trong vòng 2-3 năm. Ung thư tiên liệt tuyến giai đoạn kháng cắt tinh hoàn (mCRPC) trước đây được gọi là kháng với điều trị nội tiết, tuy nhiên gần đây với những hiểu biết sâu hơn về cơ chế tiến triển theo các con đường khác nhau (phụ thuộc và không phụ thuộc androgen), androgen vẫn đóng một vai trò rất quan trọng trong chức năng và phát triển của tế bào ung thư kháng cắt tinh hoàn.

\section{KẾT LUÂN}

Liệu pháp ức chế androgen là điều trị nền tảng và hiệu quả trong ung thư tiền liệt tuyến giai đoạn di căn. Cụ thể là:

- Sau 3 tháng điều trị, các triêu chứng lâm sàng đáp ứng thuyên giảm đáng kể.

- Bao gồm 71,8\% bệnh nhân lựa chọn cắt tinh hoàn ngoại khoa, $28,2 \%$ cắt tinh hoàn nội khoa.

- Thời gian sống thêm không tiến triển (PFS) trung bình là 26,61 $\pm 3,65$ tháng.
- PFS ở nhóm cắt tinh hoàn ngoại khoa là $22,62 \pm 3,45$ tháng, ở nhóm cắt tinh hoàn nội khoa là $31,44 \pm 4,64$ tháng, sự khác biệt giữa 2 nhóm không có ý nghĩa thống kê.

\section{TÀI LIÊU THAM KHẢO}

1. Ferlay J., Colombet M., Soerjomataram I. và cộng sự. (2019). Estimating the global cancer incidence and mortality in 2018: GLOBOCAN sources and methods. Int J Cancer, 144(8), 19411953.

2. Tâm L.T.K. đánh giá kết quả điều trị nội tiết ung thư tuyến tiền liệt giai đoạn iv. 136.

3. Gandaglia G., Abdollah F., Schiffmann J. và cộng sự. (2014). Distribution of metastatic sites in patients with prostate cancer: A populationbased analysis. The Prostate, 74(2), 210-216.

4. Loblaw D.A., Mendelson D.S., Talcott J.A. và cộng sứ. (2004). American Society of Clinica Oncology recommendations for the initial hormonal management of androgen-sensitive metastatic, recurrent, or progressive prostate cancer. J Clin Oncol Off J Am Soc Clin Oncol, 22(14), 2927-2941.

5. Conn P.M. và Crowley W.F. (1991). Gonadotropin-releasing hormone and its analogues. N Engl J Med, 324(2), 93-103.

6. Waxman J., Man A., Hendry W.F. và cộng sự. (1985). Importance of early tumour exacerbation in patients treated with long acting analogues of gonadotrophin releasing hormone for advanced prostatic cancer. $\mathrm{Br}$ Med J Clin Res Ed, 291(6506), 1387-1388.

7. Kaisary A.V., Tyrrell C.J., Peeling W.B. và cộng sứ. (1991). Comparison of LHRH analogue (Zoladex) with orchiectomy in patients with metastatic prostatic carcinoma. Br J Urol, 67(5), 502-508.

\title{
NGHIÊN CỨU HIẾU QUẢ CHUYỂN PHÔI NANG TRŨ ĐÔNG VÀ SỐ MộT YẾU TỐ LIÊN QUAN TẠI BẾNH VIỆN HỖ TRỢ SINH SẢN VÀ NAM HOC ĐỨC PHÚC
}

\author{
Phùng Thị Sơnn ${ }^{1}$, Nguyễn Thị Liên Hương ${ }^{2}$, Nguyễn Trung $\mathrm{Nam}^{3}$
}

\section{TÓM TẮT}

Mục tiêu: Xác định được tỷ lệ sông sau rã đông của phôi nang và xác định tỷ lệ có thai của chuyển phôi nang trữ đông. Đối tượng và phương pháp nghiên cứu: Nghiên cứu hồi cứu, đánh giá tỷ lệ sống

\footnotetext{
${ }^{1}$ Bệnh Viện Hỗ trợ sinh sản và Nam học Đức Phúc ${ }^{2}$ Bệnh viện Phụ Sản Trung Ương

${ }^{3}$ Viện Công nghệ sinh học - Viện Hàn lâm Khoa học và Công nghệ Việt Nam

Chịu trách nhiệm chính: Phùng Thi Sơn

Email: sonphunghus@gmail.com

Ngày nhận bài: 3.8.2021

Ngày phản biện khoa học: 30.9.2021

Ngày duyệt bài: 6.10 .2021
}

của phôi nang sau rã đông và tỷ lê có thai của 365 trường hợp chuyển phôi nang tại Bệnh viện Hỗ trơ sinh sản (HTSS) và Nam học Đức P̉húc, trong thời gian từ tháng 1 đến hết tháng 8 năm 2021. Kết quả: Từ tháng 1/2021 đến tháng 8/2021 có 365 trường hợp phù hợp tiêu chuẩn nghiên cứu. Tỷ lệ sống sau rã đông 99,85\%. Tỷ lệ $\beta$-hCG dương tính và tỷ lệ mang thai lâm sàng của nhóm này lần lượt là $74,79 \%$ và $67,12 \%$. Tỷ lệ làm tổ của phôi là 40,35 \%. Kết luận: Kết quả có thai là khá cao khi chuyển phôi nang trữ đông và trường hợp tiên lượng tốt chỉ nên chuyển 1 phôi có chất lượng tốt hoặc phôi trung bình nên chuyển kèm thêm 1 phôi tốt, khá, trung bình.

\section{SUMMARY \\ A STUDY ON FROZEN EMBRYO TRANSFER EFFECIENCY AND SOME AFFECTED FACTORS}

